\title{
Electrical Characterization of a 4H-SiC JFET Wafer: DC Parameter Variations for Extreme Temperature IC Design
}

\author{
Philip G. Neudeck, a ${ }^{\text {, }}$ Liangyu Chen², David J. Spry", \\ Glenn M. Beheim ${ }^{1}$ and Carl W. Chang ${ }^{3}$ \\ ${ }^{1}$ NASA Glenn Research Center, 21000 Brookpark Road, MS 77-1, Cleveland, OH 44135 USA \\ ${ }^{2}$ Ohio Aerospace Institute, 21000 Brookpark Road, MS 77-1, Cleveland, OH 44135 USA \\ ${ }^{3}$ Vantage Partners LLC, 21000 Brookpark Road, MS 77-1, Cleveland, OH 44135 USA \\ âNeudeck@nasa.gov
}

Keywords: 4H-SiC, JFET, High Temperature, Wafer Map, I-V, Oven Testing

\begin{abstract}
This work reports DC electrical characterization of a $76 \mathrm{~mm}$ diameter 4H-SiC JFET test wafer fabricated as part of NASA's on-going efforts to realize medium-scale ICs with prolonged and stable circuit operation at temperatures as high as $500{ }^{\circ} \mathrm{C}$. In particular, these measurements provide quantitative parameter ranges for use in JFET IC design and simulation. Larger than expected parameter variations were observed both as a function of position across the wafer as well as a function of ambient testing temperature from $23{ }^{\circ} \mathrm{C}$ to $500{ }^{\circ} \mathrm{C}$.
\end{abstract}

\section{Introduction}

In order for $\mathrm{SiC}$ electronics to benefit applications in the harshest envisioned environments, circuit operation for thousands of hours or more in the demanding application conditions is necessary. The NASA Glenn Research Center previously has demonstrated prolonged and stable packaged operation of very simple $(<5$ transistors) $6 \mathrm{H}$-SiC junction field-effect transistor (JFET) integrated circuits (ICs) for thousands of hours at $500{ }^{\circ} \mathrm{C}$ in air ambient [1,2]. Others have demonstrated more complicated SiC ICs, but without reporting thousands of hours of stable electrical operation at $500{ }^{\circ} \mathrm{C}[3,4]$. This work reports electrical characterization of a $76 \mathrm{~mm}$ diameter 4H-SiC JFET test wafer fabricated as part of NASA's on-going efforts to realize mediumscale ICs (>100 transistors/chip) with prolonged and stable circuit operation at ambient temperature (T) as high as $500{ }^{\circ} \mathrm{C}$. In particular, these measurements provide quantitative DC parameter ranges for use in JFET IC design and simulation, both as a function of position across the wafer as well as a few initial measurements of parameter changes with $\mathrm{T}$ from $23{ }^{\circ} \mathrm{C}$ to $500{ }^{\circ} \mathrm{C}$.

\section{Experimental}

All measurements were carried out on devices fabricated at NASA Glenn starting from a single 76-mm diameter $4 \mathrm{H}-\mathrm{SiC}$ wafer with epilayers purchased in 2009 [5] (Fig. 1). The 4H-SiC JFET structure features dry-etch patterned $\mathrm{p}^{+}$gate and $\mathrm{n}$ channel epilayers with gate length $\left(\mathrm{L}_{\mathrm{G}}\right)$ and minimum feature size of $6 \mu \mathrm{m}$. In addition to a patterned high-dose ion implantation to facilitate n-layer ohmic contact formation, a self-aligned shallow $\mathrm{N}$ implant $\left(3.6 \times 10^{12}\right.$ $\mathrm{cm}^{-2}$ at $70 \mathrm{keV}$ ) was performed at room temperature into surface-exposed n-epilayer regions to reduce parasitics [6].

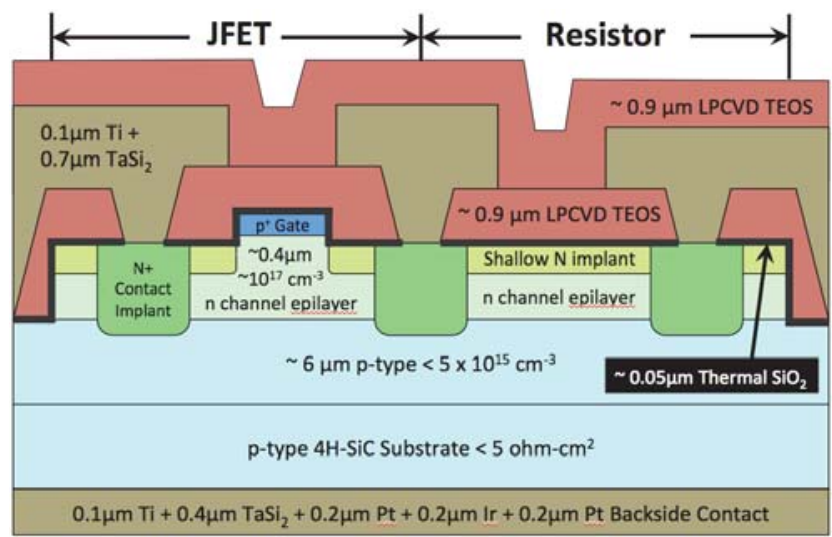

Fig. 1. Simplified cross-sectional schematic of NASA Glenn $4 \mathrm{H}-\mathrm{SiC}$ JFET and resistor (sharing common ntype layer mesa). 
Wafer mapping was carried out at $\mathrm{T}=23{ }^{\circ} \mathrm{C}$ on a probing system using source-measure units for DC current vs. voltage (I-V) measurements. Data was collected from diagnostic process test chips arrayed across the wafer every $9 \mathrm{~mm}$. Mapped test devices included $\mathrm{W}_{\mathrm{G}}=12 \mu \mathrm{m} / \mathrm{L}_{\mathrm{G}}=6 \mu \mathrm{m} \mathrm{JFETs}$, $\mathrm{L}_{\mathrm{R}}=120 \mu \mathrm{m} \times \mathrm{W}_{\mathrm{R}}=12 \mu \mathrm{m}$ (= 10 squares) resistors, and $54 \mu \mathrm{m}$ wide transmission line method (TLM) devices with $48 \mu \mathrm{m}$ wide $\mathrm{x} 24 \mu \mathrm{m}$ long contact openings at separation spacings of $12 \mu \mathrm{m}, 66 \mu \mathrm{m}$, and $126 \mu \mathrm{m}$. Negative substrate bias was applied for most measurements consistent with the intended circuit approach of Krasowski [2,7]. Measured resistance (R) values were calculated from $\mathrm{I}-\mathrm{V}$ slopes while JFET threshold voltages $\left(\mathrm{V}_{\mathrm{T}}\right)$ were calculated from $\mathrm{x}$-intercepts of the linear region of $\sqrt{I_{D}}\left(\mathrm{I}_{\mathrm{D}}=\right.$ drain current $)$ vs. gate voltage $\left(\mathrm{V}_{\mathrm{G}}\right)$ plots at drain voltage $\left(\mathrm{V}_{\mathrm{D}}\right)$ of $20 \mathrm{~V}$. After mapping, the wafer was diced into $3 \mathrm{~mm}$ x $3 \mathrm{~mm}$ chips. Three chips were then custom-packaged [8] and mounted in an oven and connected to outside-oven instruments via gold wires with fiberglass insulation for carrying out DC I-V measurements from $23{ }^{\circ} \mathrm{C}$ to $500{ }^{\circ} \mathrm{C}$.

\section{Results and Discussion}

Room Temperature Wafer Mapping. Room temperature prober mapping reveals significant radial variation in $n$-channel electrical properties across the epi-wafer. Fig. 2 illustrates the variation of $V_{T}$ measured from $12 \mu \mathrm{m} / 6 \mu \mathrm{m}$ test JFETs across the wafer. The smallest $V_{T}$ 's (i.e., closest to 0 V) occur in the central region of the wafer, and significantly increase as position progresses outward towards the wafer edge. For the JFET structure of Fig. 1, $\mathrm{V}_{\mathrm{T}}$ is determined by the $\mathrm{n}$-channel epilayer immediately underneath the JFET gate. As there are no processing changes to this electrically critical region following epilayer growth (such as implantation or etching), the observed $\mathrm{V}_{\mathrm{T}}$ variation directly reflects the variation in doping concentration and thickness of the as-grown nchannel epilayer. Therefore, the n-epilayer sheet charge density and conductivity (a function of nepilayer doping $\mathrm{x}$ thickness product) in the wafer central region is significantly smaller than at the wafer periphery.

In contrast to measured $V_{T}$ that is strictly a function of the as-grown epilayers, measured resistance values have additional dependence on post-epilayer processing such as ion implantation and contacts. Fig. 3 shows the measured variation in JFET drain-to-source resistance $\left(\mathrm{R}_{\mathrm{DS}}\right)$ of the $12 \mu \mathrm{m} / 6 \mu \mathrm{m}$ test JFETs, $L_{R}=120 \mu \mathrm{m} \times \mathrm{W}_{\mathrm{R}}=12 \mu \mathrm{m}$ resistors $\left(\mathrm{R}_{10}\right)$, and sheet resistance ( $\left.\mathrm{R}_{\text {Sheet }}\right)$ extracted from TLMs plotted as a function of radial distance from the wafer center. To better compare the magnitude of positional variation, plotted $\mathrm{R}$ values are respectively normalized to the statistical mean of resistance accumulated for each device type. Linear data fits for the respective device types are shown as dashed lines. The resistances exhibit spatial variation across the wafer generally consistent with the observed $V_{T}$ variation, in which higher $\mathrm{R}$ values correspond to central wafer regions of less negative $\mathrm{V}_{\mathrm{T}}$ (i.e., less $\mathrm{n}$ epilayer conductivity).

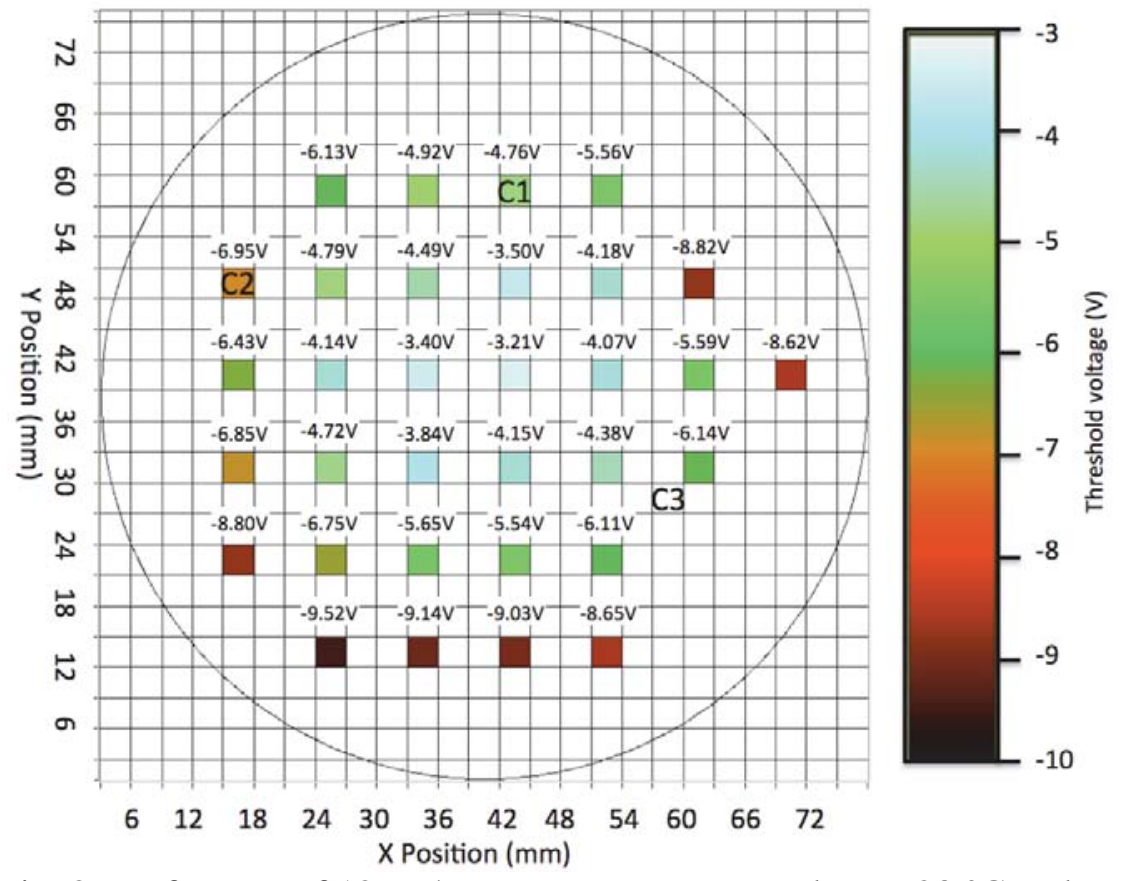

Fig. 2. Wafer map of $12 \mu \mathrm{m} / 6 \mu \mathrm{m}$ JFET $\mathrm{V}_{\mathrm{T}}$ measured at $\mathrm{T}=23{ }^{\circ} \mathrm{C}$ and $\mathrm{V}_{\text {Substrate }}=-15 \mathrm{~V}$. Locations of packaged chips C1, C2 \& C3 are shown. 
However, the spatial dependence of $\mathrm{R}_{10}$ and $\mathrm{R}_{\text {Sheet }}$ is significantly weaker than the spatial variation of $R_{D S}$ (i.e., reduced slope in the linear fit dashed lines). This is inferred to arise from the shallow implant extending the entire length of TLMs and $\mathrm{R}_{10}$ resistors (Fig. 1) with good uniformity across the wafer surface, whereas $\mathrm{R}_{\mathrm{DS}}$ is dominated by the spatially more-variant n-epilayer resistance of the JFET channel region that has no implant.

With the exception of two high-resistance outlier points, specific contact resistivity extracted from measured TLM data for the $\mathrm{Ti} / \mathrm{TaSi}_{2}$ contact [9] to high-dose $\mathrm{N}$ source/drain implanted regions ranged from $2 \times 10^{-4}$ to $2 \times$ $10^{-5} \Omega-\mathrm{cm}^{2}$ and did not exhibit an experimentally significant trend as a function of wafer position. The fact that measured $\mathrm{R}_{10}$ is larger than 10 squares $\mathrm{x}$ TLM $\mathrm{R}_{\text {Sheet }}$ indicates that end resistance and contact resistance effects are non-negligible.

Temperature Dependence of Packaged Devices. The ratio of transistor ON-state current to OFF-state current degrades with increasing $\mathrm{T}$ and often dictates maximum useful temperature of an IC technology for an application. Even at $500{ }^{\circ} \mathrm{C}$, all three packaged $4 \mathrm{H}-\mathrm{SiC}$ JFETs demonstrated OFF-state currents below $0.1 \mu \mathrm{A}$ and $\mathrm{ON}$ to OFF state current ratios better than 900. Fig. 4 compares the turn-off characteristics of two packaged JFETs with significantly different $\mathrm{W}_{\mathrm{G}}$ and $\mathrm{V}_{\mathrm{T}}$ at $23{ }^{\circ} \mathrm{C}$ and $500{ }^{\circ} \mathrm{C}$. $\mathrm{V}_{\mathrm{T}}$ exhibited nearly linear change over this $\mathrm{T}$ range, from $-4.47 \mathrm{~V}$ and $-6.15 \mathrm{~V}$ at $23{ }^{\circ} \mathrm{C}$ to $-5.06 \mathrm{~V}$ and $-6.54 \mathrm{~V}$ at $500{ }^{\circ} \mathrm{C}$ for the respective $\mathrm{W}_{\mathrm{G}}=12 \mu \mathrm{m}$ and $\mathrm{W}_{\mathrm{G}}=192 \mu \mathrm{m}$ devices. Linear fits of $\mathrm{V}_{\mathrm{T}}$ vs. $\mathrm{T}$ data (recorded at $\mathrm{T}=23,100,200,300,400$, and $500{ }^{\circ} \mathrm{C}$ ) for these two JFETs yield slopes of $-1.20 \mathrm{mV} /{ }^{\circ} \mathrm{C}$ and $-0.796 \mathrm{mV} /{ }^{\circ} \mathrm{C}$, respectively.

The changes observed in measured device resistance from $23{ }^{\circ} \mathrm{C}$ to $500{ }^{\circ} \mathrm{C}$ are comparatively illustrated in Fig. 5. For more clear comparison of relative change magnitudes, all values are plotted normalized to each respective device's measured value at $23{ }^{\circ} \mathrm{C}\left(\mathrm{R}_{23^{\circ} \mathrm{C}}\right)$. Qualitatively consistent with prior understanding, resistances for all tested devices increase with temperature presumably due to declining electron mobility arising from increased thermal carrier scattering in the n-doped current-carrying device regions [10]. Importantly however, the resistor devices plotted in Fig. 5 exhibit substantially larger resistance increase (not far from 2X larger at $500{ }^{\circ} \mathrm{C}$ ) with temperature than JFET devices, even for cases where the JFET and resistor physically reside on the same packaged die. Packaged TLM device behavior preliminarily indicates that this is caused by the greater temperature sensitivity of the $n$ type sheet resistance (epi with implant, see TLM $\mathrm{R}_{\text {Sheet}}$, Fig. 5) relative to the JFET n-channel resistance (epi without implant). Specific contact resistivity, which changes only slightly from $300{ }^{\circ} \mathrm{C}$ to $500{ }^{\circ} \mathrm{C}$ (remaining near $4 \times 10^{-4} \Omega$ $\mathrm{cm}^{2}$ ), did not exhibit comparable temperature dependence as measured resistor values.

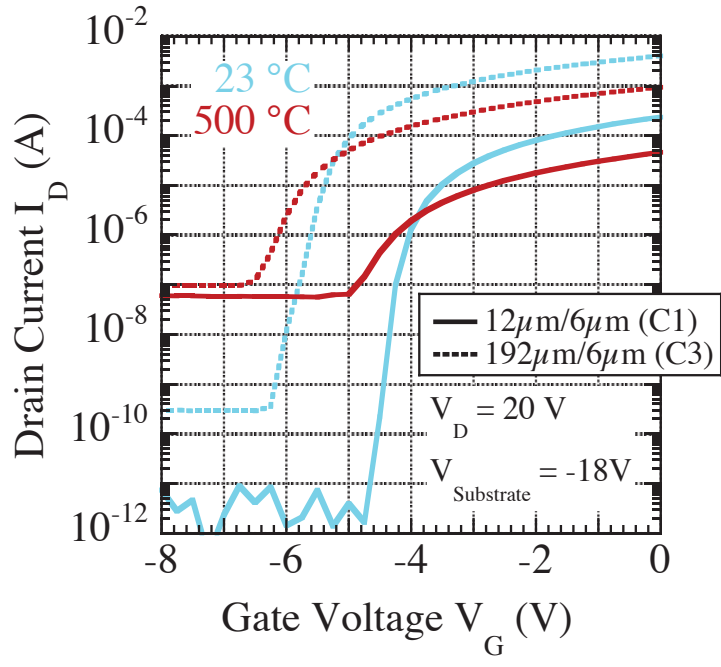

Fig. 4. Turn-off characteristics of two hightemperature packaged $4 \mathrm{H}-\mathrm{SiC}$ JFETs at $23{ }^{\circ} \mathrm{C}$ and $500{ }^{\circ} \mathrm{C}$. See Fig. 2 for wafer locations of chips $\mathrm{C} 1$ and $\mathrm{C} 3$. 
The temperature-induced resistance increase of resistors (relative to room temperature $\mathrm{R}$ value) shown in Fig. 5 is significantly larger than reported in prior studies of similar $4 \mathrm{H}-\mathrm{SiC}$ n-channel devices [10]. Furthermore, the increasing disparity between resistor R vs. JFET $\mathrm{R}$ at higher $\mathrm{T}$ is much greater than the negligible disparity obtained comparing very similar JFETs and resistors previously implemented in $6 \mathrm{H}-\mathrm{SiC}$ [2]. As discussed in [2,7], a key basis for simplified design of SiC JFET ICs that function over an extremely broad temperature range without changes to input voltages is the fact that $\mathrm{SiC}$ resistors and JFETs should almost identically track in the magnitude of their conduction parameter changes with temperature. At a minimum, the larger disparities illustrated for high $\mathrm{T}$ in Fig. 5 are likely to undesirably increase the $\mathrm{T}$ dependence of simple analog inverting and

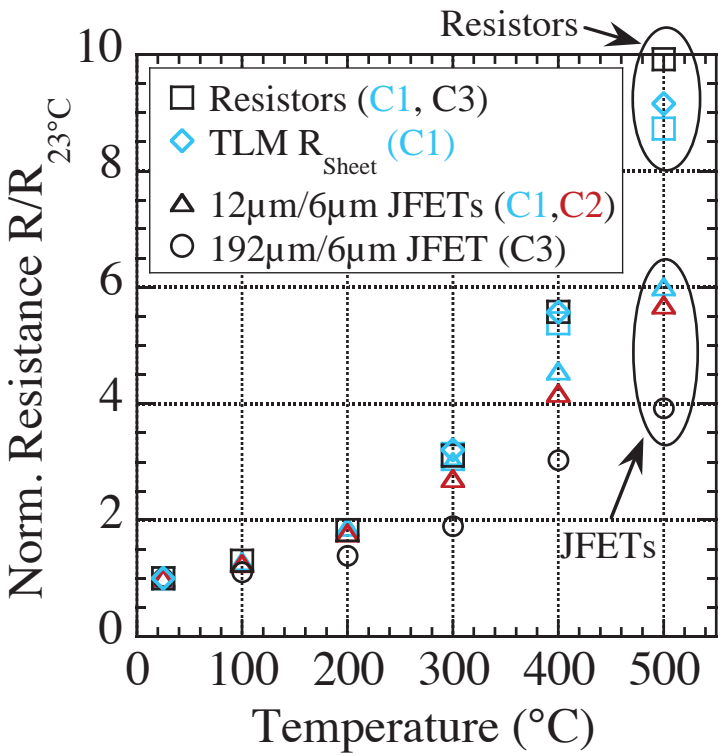

Fig. 5. Normalized resistance $\left(\mathrm{R} / \mathrm{R}_{\left.23^{\circ} \mathrm{C}\right)}\right.$ of packaged devices measured vs. $T$ with $V_{\text {Substrate }}=-18 \mathrm{~V}$. See Fig. 2 for wafer locations of chips C1, C2, and C3. differential amplifier sub-circuits. Digital logic chip functionality will be less affected than analog circuits due to the fact that logic circuit output voltages primarily rely on $\mathrm{V}_{\mathrm{T}}$ and power supply voltages [2,7]. Further study is needed to elucidate the root physical mechanisms behind the larger than expected $\mathrm{R}$ value disparity with $\mathrm{T}$. Until negated (perhaps) via processing changes, this $\mathrm{R}$ change disparity between device types at high $\mathrm{T}$ should be accounted for in modeling and design of extreme temperature 4H-SiC JFET ICs.

\section{Summary}

Important relative changes in DC parameters of epitaxial n-channel 4H-SiC JFETs and resistors as a function of wafer position and temperature have been measured. While parameter value spreads/changes measured in this work can be somewhat accommodated via circuit design and supply voltage adjustments, significantly reduced parameter variation would yield IC chips with more uniform electrical functionality regardless of temperature or chip location on the wafer.

Acknowledgments. Work conducted at NASA Glenn under the Fundamental Aeronautics Program (Aeronautical Sciences Project) and Aviation Safety Program (Vehicle Systems Safety Technologies Project). This work was enabled by the support of K. Moses, J. Gonzalez, D. Lukco, A. Biaggi-Labiosa, B. Osborn, R. Buttler, G. Hunter, D. Culley, and L. Matus.

\section{References}

[1] D. J. Spry et al., Materials Science Forum 600-603, 1079 (2008).

[2] P. G. Neudeck et al., Physica Status Solidi A 206, 2329 (2009).

[3] C.-P. Chen et al., 2014 IMAPS Int. Conf. on High Temperature Electronics, p. 72 (2014).

[4] L. Lanni, B. G. Malm, M. Ostling and C.-M. Zetterling, this conference.

[5] Cree, Inc., http://www.cree.com.

[6] P. G. Neudeck, U. S. Patent No. 7,935,601 (3 May 2011).

[7] M. J. Krasowski, U. S. Patent No. 7.688,117 (30 March 2010).

[8] L.-Y. Chen and J.-F. Lei, Packaging of Harsh Environment MEMS Devices, in: M. Gad-el.Hak (Ed.), MEMS Design and Fabrication, CRC Press, Boca Raton, Florida USA, 2006, p. 12-1.

[9] R. S. Okojie, D. Lukco, Y. L. Chen, and D. J. Spry, J. Appl. Phys. 91, 6553 (2002).

[10] C. J. Scozzie, F. B. McLean, and J. M. McGarrity, J. Appl. Phys. 81, 7687 (1997). 